Received 00th January 20xx Accepted 00th January $20 x x$ DOI: $10.1039 / x 0 x \times 00000 x$

\section{Hydroamination of non-activated alkenes with ammonia: A holy grail in catalysis}

\author{
Stéphane Streiff ${ }^{\mathrm{a}}$ and François Jérôme ${ }^{\mathrm{b}} *$
}

\begin{abstract}
Alkyl amines represent an important class of chemicals with multiple applications in our daily life. Among the different routes to alkyl amines, the catalytic hydroamination of alkenes with amines is of high interest mainly because it occurs in a $100 \%$ atom-economical fashion. To circumvent thermodynamic limitations, activated alkenes or activated amines are essentially employed in such reaction. To date, the catalytic hydroamination of cheap and abundant non-activated (linear) alkenes with ammonia, the simplest amine, remains an unsolved reaction by catalysis. This tutorial review covers the advances reported so far in the intermolecular hydroamination of non-activated linear alkenes with simple alkyl amines, with a special interest on ammonia. Focusing on thermodynamics, catalysis and emerging technologies, we aim at providing new perspectives to look at this challenging reaction from a different point of view. In particular, we highlight that the generation of amino radicals from $\mathrm{NH}_{3}$ using "physics activation" is a potential source of inspiration to (i) reduce energy barriers and (ii) reverse the regioselectivity to complete anti-Markovnikov addition.
\end{abstract}

\section{Introduction}

Amines are a versatile class of compounds widely used in industry for the manufacture of agricultural chemicals, solvents, polymers, feed and food additives, cleaning products, pharmaceuticals, gas and water treatment, personal care products, cement, paint and coatings, textile, etc. Amines represent a market of 6.1 million metric tons, ${ }^{[1]}$ generating a turnover of USD 14.4 billion in 2016. With the exponential increase of the world population, the demand of our society for amine-based products is dramatically increasing and this market is expected to growth at an annual rate of $8.3 \%$, with a predicted turnover of USD 29.3 Billion by 2025 . $^{[1]}$ The world consumption of amines per sector is provided in Figure 1.

Among amines, alkyl amines represent one of the most important targets with a production expected to increase at about 2.5\% per year during 2017-22, mostly boosted by the Asian demand for chemicals in crop protection and surfactants. $^{[1-3]}$ The demand of alkyl amines in crop protection was recorded to be the highest among all applications, and is expected to witness growth at nearly $8 \%$ over the forecast period, on account of growth of the agricultural sector in several emerging economies worldwide. The fatty amines product segment accounted for the secondlargest share of the overall industry revenues in 2016. This segment is expected to grow at an annual rate of $8.6 \%$ during the forecast period, on account of increasing use of the product in the manufacture of corrosion inhibitors, flotation agents, and anti-cackling agents. ${ }^{[4]}$ Many chemical companies are involved in the manufacturing of alkyl amines with Akzo Nobel, BASF, Dow, Eastman, Huntsman, SOLVAY, Arkema,

\footnotetext{
a. Institut de Chimie des Milieux et Matériaux de Poitiers, University of Poitiers, ENSIP, 1 rue Marcel Doré, 86073 Poitiers, France. E-mail:

francois.jerome@univ-poitiers.fr.

Eco-Efficient Products and Processes Laboratory, UMI 3464 CNRS/Solvay, 3966 Jin Du Road, Shanghai 201108 (CHINA).
}

INEOS, KAO, Taminco, Clariant being among the major actors.

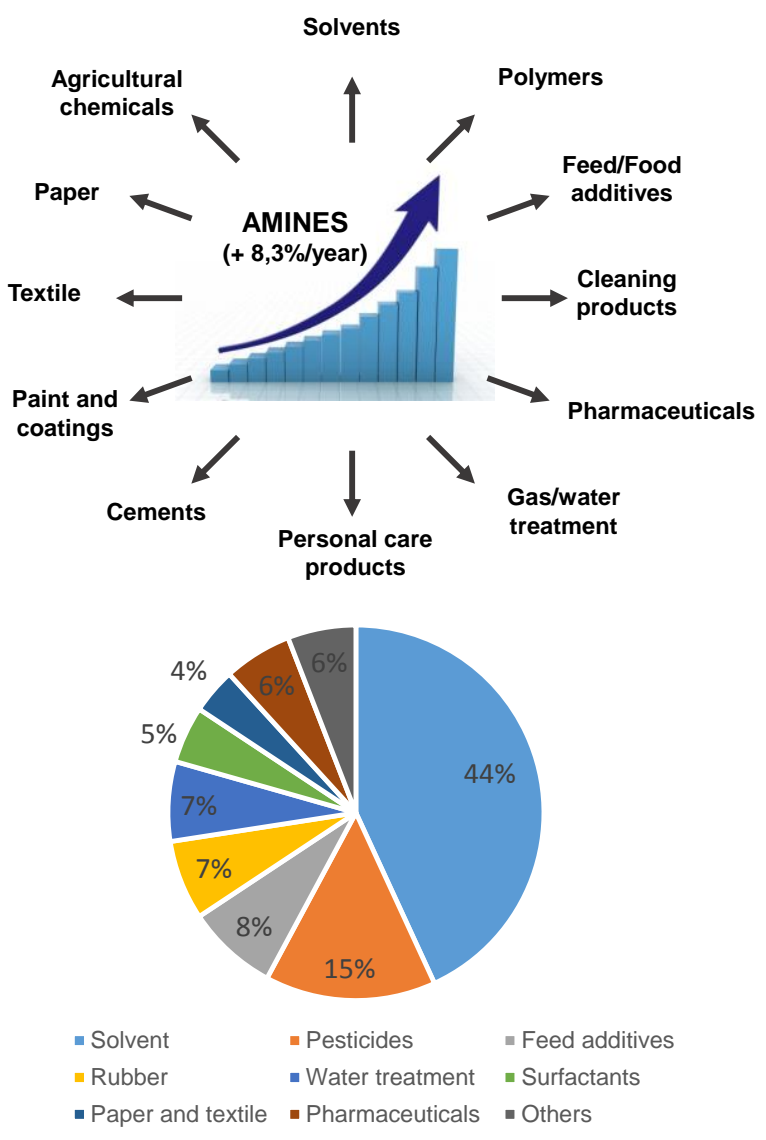

Figure 1. Main applications of amines (top) and world consumption of aliphatic amines per sector (right). Reproduced from ref 2 .

\section{Industrial routes to alkyl amines}

According to the nature of the alkyl amines (primary secondary, tertiary), different routes were commercialized 
(Fig. 2). Tertiary and secondary alkyl amines are industrially produced either by catalytic dehydrogenative coupling of alkyl alcohols with primary or secondary alkyl amines or by catalytic reductive amination of ketone/aldehydes. For instance, fatty tertiary amines such as $N, N$ dimethylalkylamines are produced by dehydrogenative coupling of fatty alkyl alcohols

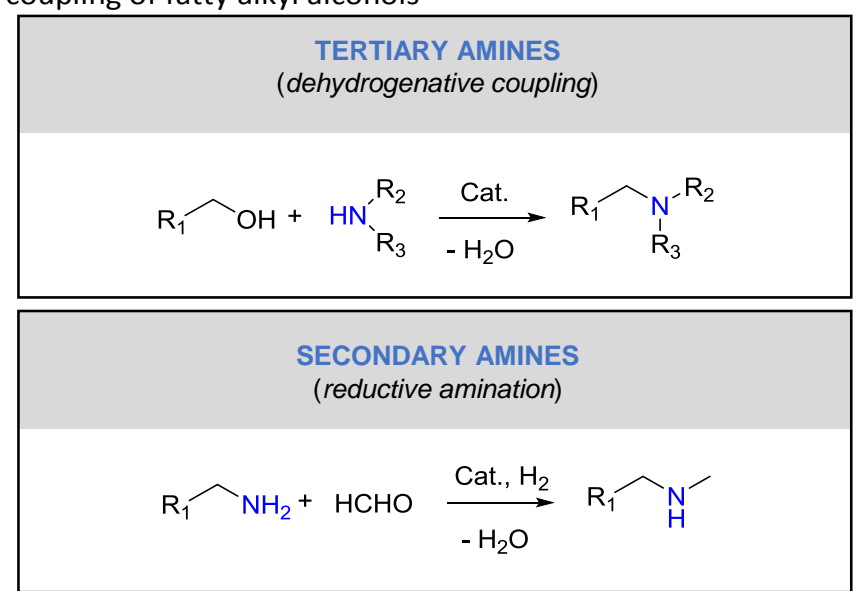

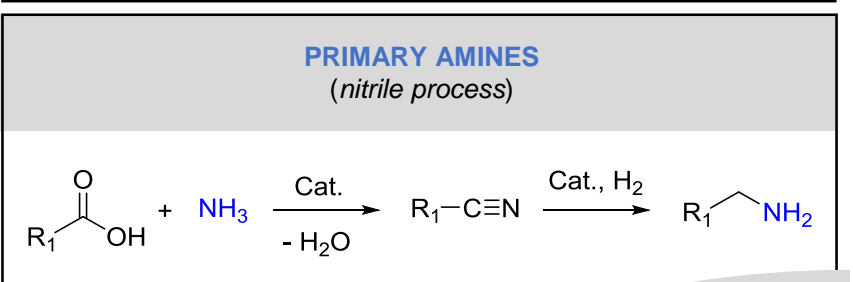

$\mathrm{R}_{1}=$ alkyl chain; Cat $=$ catalyst

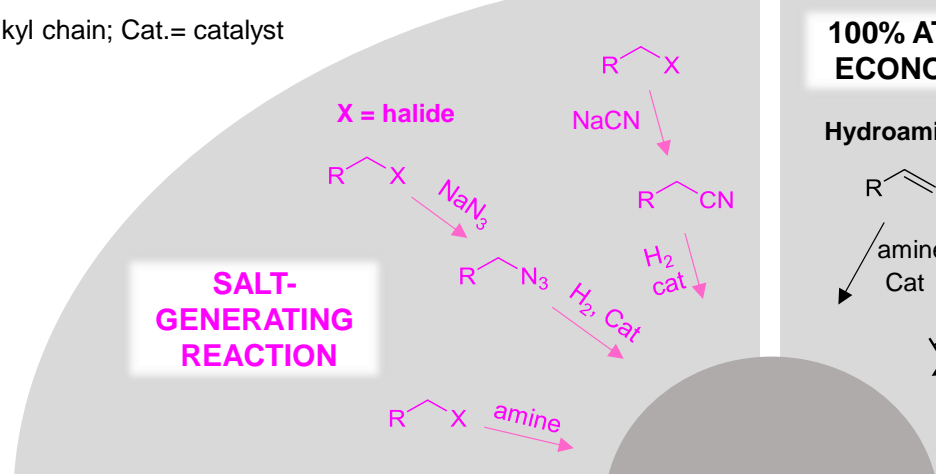

ALKYL AMINES

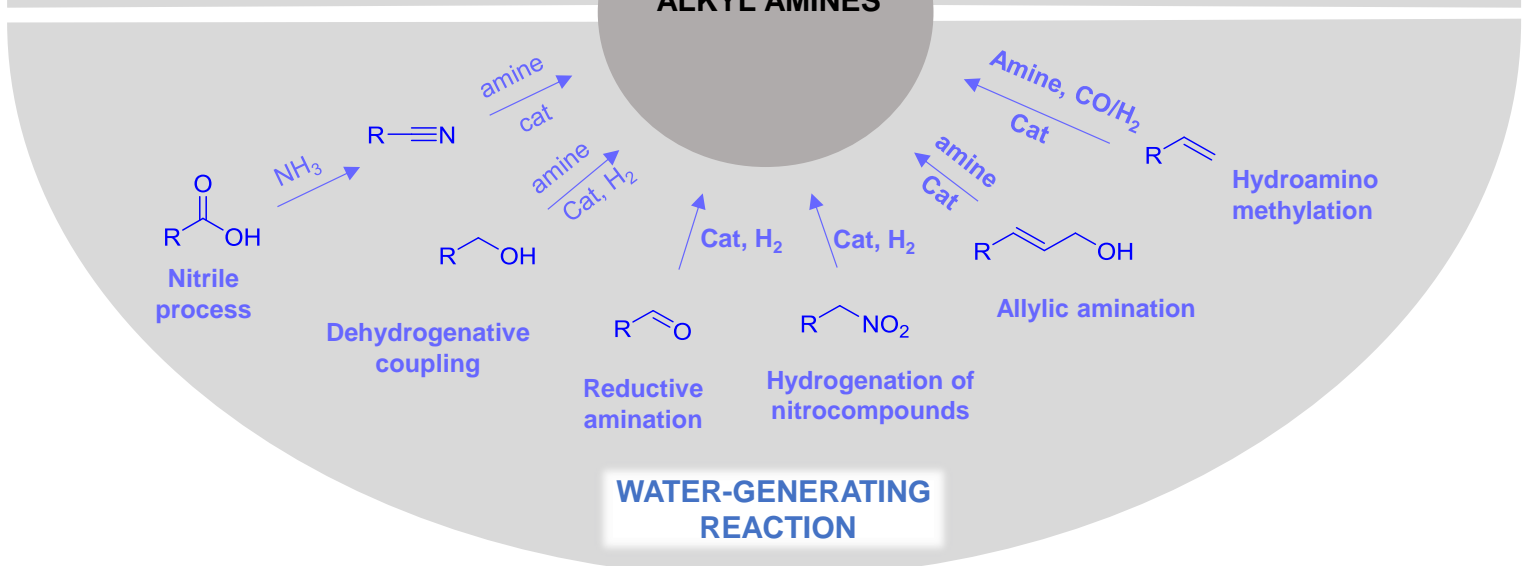

Figure 3. The different routes to alkyl amines
Figure 2. Main industrial routes to alkyl amines

with dimethylamine, while the reductive amination of primary amine with formaldehyde is a preferred pathway for the synthesis of secondary $N$-methylalkylamines. On a large scale, these two routes are unfortunately not applicable to ammonia and are thus generally not used for the synthesis of primary amines. The main reason is that primary amines in situ produced are more nucleophilic and basic than ammonia, thus (i) requiring a large excess of ammonia (i.e high pressure) and (ii) raising selectivity issue due to the concomitant formation of secondary and tertiary amines. One should mention however two exceptions (1) Nmethylamine which is industrially produced by reaction of methanol with ammonia and (2) glucamine and furfurylamine which are produced by reductive amination of glucose and furfural, respectively, with ammonia. The vast majority of primary amines are industrially produced in a two-step reaction through the "nitrile" process (Fig. 2). It involves a nitrilation of carboxylic acid with ammonia, followed by a catalytic hydrogenation. These routes are particularly employed for the synthesis of fatty primary amines (decyl-, dodecyl, hexadecylamines) and diamines such as tetra-, hexa, decamethylenediamine and meta- or para-xylylenediamine, which are employed in the fabrication of surfactants and polymers, respectively. On the other hand, primary aromatic amines such as aniline are produced by reduction of nitro rnmoounds. For instance, this process has been implemented

\section{ATOM}

\section{CONOMY}

roamination

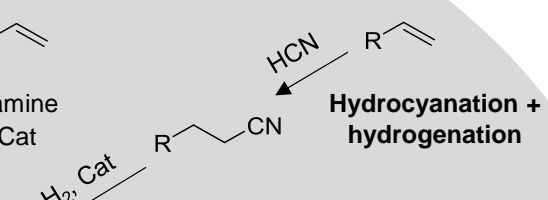

\section{amine \\ amine $>$ Telomerization}


diaminotoluene, a key intermediate in polyurethane synthesis. Aromatic amines are out of scope of this review which is focused on the hydroamination of alkenes.

It is worth mentioning that other routes are currently explored at an academic and industrial level, such as the transition metal-catalyzed allylic amination, catalytic hydroaminomethylation of alkenes, metal-catalyzed telomerization of dienes with amines and hydrocyanation/hydrogenation of alkenes. (Fig. 3). So far these routes are hardly implementable on a large scale for the production of primary alkyl amines because of (i) safety issues (e.g. $\mathrm{CO}$ and $\mathrm{HCN}$ for hydroaminomethylation and hydrocyanation reactions, respectively), (ii) the formation of waste or co-product (e.g. salts for the allylic amination) and, more importantly, (iii) selectivity issues due to the huge difficulty to stop these catalytic processes at the primary alkyl amine stage, a mixture of mono-, di- and trialkylamines being generally obtained.

\section{Catalytic hydroamination of alkenes: the royal way to alkyl amines}

Among all possible reactions, the hydroamination of alkenes with simple amines, including ammonia, is considered as a Holy Grail in chemistry because it paves the way to alkyl amines from cheap and abundant feedstocks, in a $100 \%$ atom economical fashion (i.e. no waste). ${ }^{[5-11]}$ So far, catalysis (metallic, acid, basic) has been investigated as the main toolbox for performing the hydroamination of alkenes. However, because the reaction is approximatively thermoneutral $(\Delta \mathrm{G} \sim 0 \mathrm{kcal} / \mathrm{mol}),{ }^{[12,13]}$ most of reported works involved either activated amines (e.g. aniline, sulfonamide, arylamine, benzamide, carbamate, hydroxylamine ester, etc.) or activated alkenes (i.e featuring ring strain, conjugation, or substitution with electron withdrawing groups). The hydroamination of non-activated $\mathrm{C}=\mathrm{C}$ bonds with amines has been shown feasible, but mostly exclusively though intramolecular hydroamination reactions. In these examples, the ring closing is the main thermodynamic driver to turn these hydroamination reactions into success. ${ }^{[12,13]}$ In this context, Bronsted acid, rare-earth, alkaline earth, group III and

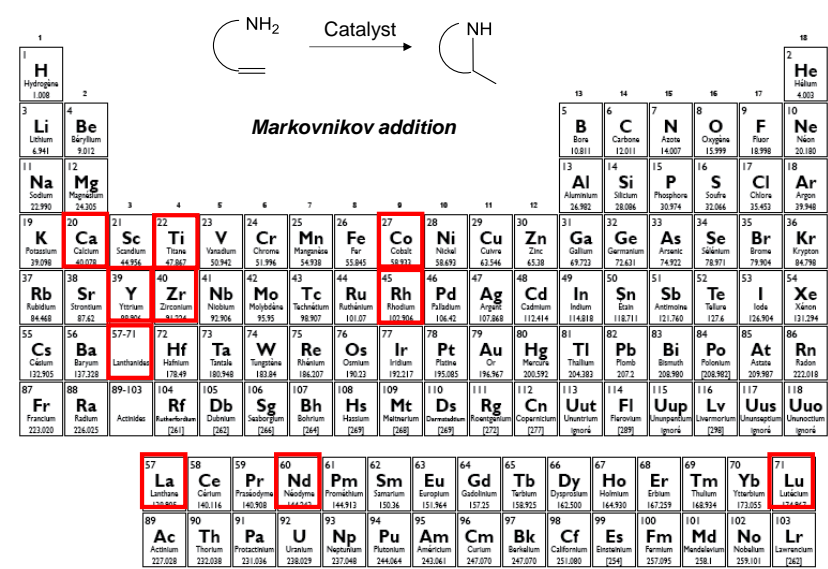

Figure 4. The main elements used in the intramolecular hydroamination of alkenes with primary amines.

IV metals and cobalt or rhodium-based complexes were reported as the most efficient catalysts (Fig. 4). ${ }^{[5-11]}$ Although of high interest from a scientific point of view, the assynthesized amines have unfortunately only a niche market.

The intermolecular hydroamination of non-activated alkenes with primary/secondary alkyl amines is much more appealing, but it lacks a thermodynamic driving force. In addition, this reaction is also partly inhibited by the strong coordinating properties of amines on the metal center, which prevent the coordination of the alkene. As a result, this reaction has been reported sporadically. A pioneering work of Coulson showed that rhodium and iridium complexes such as $\mu$-dichlorotetraethylene-dirhodium (I), $\mathrm{Rhl}_{3} .3 \mathrm{H}_{2} \mathrm{O}$, $\mathrm{Rh}\left(\mathrm{NO}_{3}\right)_{3}$ and $\mathrm{IrCl}_{3} .3 \mathrm{H}_{2} \mathrm{O}$ were capable of catalyzing the hydroamination of ethylene with secondary amines in THF (Fig. 5). ${ }^{[14]}$ Because of thermodynamic limitations, the hydroamination reaction was conducted at a high temperature $\left(200^{\circ} \mathrm{C}\right)$, and thus at a very high pressure of ethylene. Tertiary amines were obtained in $36-70 \%$ yield, but the reaction scope was restricted to ethylene and secondary amines such as dimethylamine, pyrrolidine and piperidine. Primary amines and ammonia were not eligible. Furthermore, the catalyst suffers from a rapid deactivation. ${ }^{[15]}$

Later, Beller reported that strong bases such as LiNEt $_{2}$ catalyze the hydroamination of ethylene with diethylamine in the presence of tetramethylethylene diamine at only $80^{\circ} \mathrm{C}$, affording the hydroaminated product with up to $90 \%$ yield (Fig. 5). ${ }^{[16]}$ However, low yields $(<10 \%)$ were obtained using a higher alkene such as 1-hexene. Hultzsch reported the asymmetric intermolecular hydroamination of linear alkenes with simple amines in the presence of yttrium and lutetiumbased homogenous catalysts (Fig. 5). ${ }^{[17]}$ Hydroamination products were successfully obtained with $25-80 \%$ yield, with high Markovnikov selectivity. In this work, the coordination of the linear alkene on the metal center was facilitated thanks to the use of bulky amines such as benzylamines and cyclopentyl amines, together with the utilization of bulky ligands on the catalyst, and a 15-fold excess of alkene.

Modular control of regioselectivity poses an additional challenge, as these methods provide only Markovnikov addition products. Being able to reverse the regioselectivity to Anti-Markovnikov is highly desirable, notably to access linear primary amines which exhibit a very broad spectrum of applications, but this remains a difficult task. Inspired by a previous study on intramolecular hydroamination, ${ }^{[18]}$ Knowles has developed several photocatalytic methods for alkene hydroamination, involving an iridium-based photoredoxcatalyst, an aryl thiol as a co-catalyst (hydrogen atom donor), visible light irradiation, and cyclic secondary amines (Fig. 5). ${ }^{[19]}$ The originality of this work is the in situ formation of an aminium radical cation, which undergoes addition to alkenes with exclusive anti-Markovnikov regioselectivity, thanks to the stabilization of a secondary 
carbon centered radical (Fig. 6). Additionally, this radical mediated mechanism lowers the activation energy barriers of the reaction, thus allowing the reaction to proceed at low temperature $\left(45^{\circ} \mathrm{C}\right)$, a positive aspect regarding

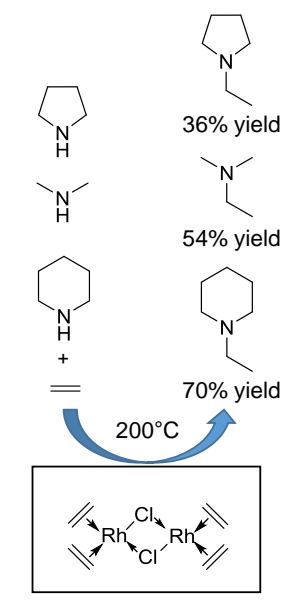

Very limited substrate scope

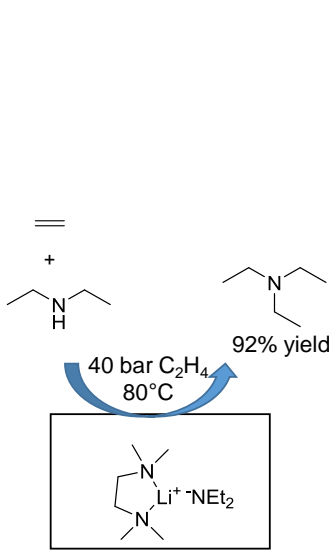

Low yield with higher olefines $(<10 \%)$

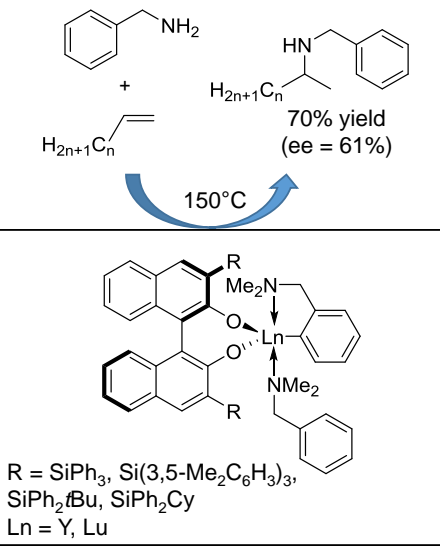

Markovnikov addition of primary amines

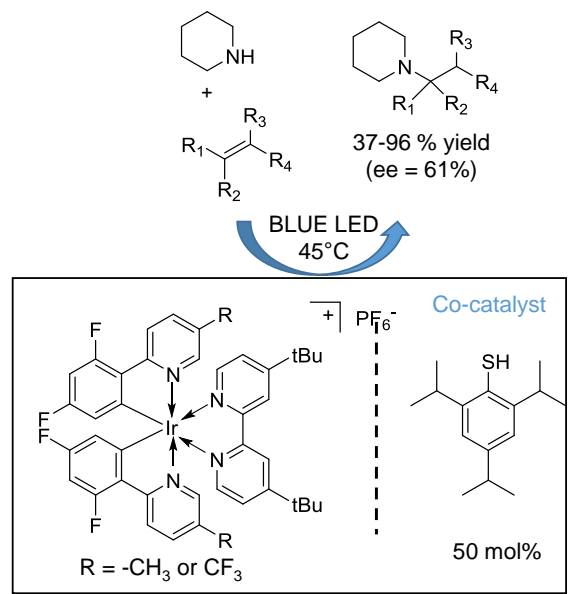

Anti-Markovnikov addition and broad substrate scope

\section{1: Coulson}

Figure 5. Progresses in the intermolecular hydromination of non-activated alkenes with simple amines

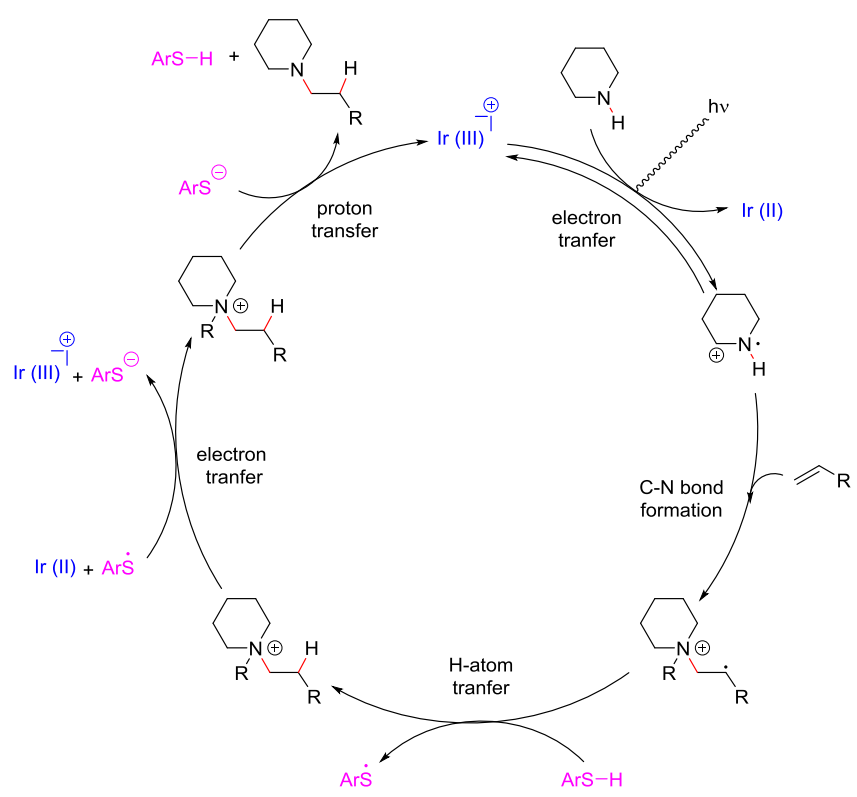

Figure 6. Iridium-based photoredox catalyst for hydroamination of unactivated alkenes with simple secondary amines. Adapted from ref. 19 with permission from AAAS, copyright 2020.

thermodynamics. As a result, this work paves the way to a broad range of alkyl amines, with fair to excellent yields, which are not accessible by other catalytic routes. The main inconvenient is the large excess of aryl thiol required to trap the in situ formed intermediate carbon centered radical (50 mol \%) (Fig. 6).

In 2019, this concept was successfully transposed to primary amines, which is an even more complex reaction due to the highly endergonic nature of this reaction. ${ }^{[20]}$ In this work, the $\left[\operatorname{Ir}\left(\mathrm{dF}(\mathrm{Me}) \mathrm{ppy}_{2}(\mathrm{dtbbpy})\right] \mathrm{PF}_{6}\right.$ photoredox catalyst was changed to the more oxidizing $\left[\operatorname{Ir}\left(\mathrm{dF}\left(\mathrm{CF}_{3}\right) \text { ppy }\right)_{2}\left(4,4-\mathrm{d}\left(\mathrm{CF}_{3}\right)\right.\right.$ -
bpy)]PF 6 catalyst. The in situ produced primary aminium radical cation was much more reactive with the alkene than the secondary ones, thus limiting the side back-electron transfer from the reduced $\operatorname{Ir}(I I)$ state responsible for the regeneration of the starting amine. Best results were obtained using dioxane as a reaction solvent.

Scientifically speaking, these works bring an important lesson: a radical mechanism may be more judicious for hydroamination reaction as (1) it reverses the regioselectivity of the reaction to anti-Markovnikov and (2) the addition of aminium radical is nearly barrier less, allowing the temperature of the reaction to be reduced, a very positive aspect as regards thermodynamics. This claim is also in line with the work of Schmidt, ${ }^{[21]}$ who showed that nitrogen centred radical (phthalimidyl radicals) readily reacted with a wide range of alkenes in an anti-Markovnikov fashion at only $50-90^{\circ} \mathrm{C}$.

\section{Ammonia, the insolent chemical that resists the efforts of catalysis}

Despite all these significant advances in hydroamination reaction, all attempts to use $\mathrm{NH}_{3}$ failed and none of these previous routes is capable of yielding the valuable primary amines. So far, the hydroamination of non-activated alkenes with $\mathrm{NH}_{3}$, the simplest and the most abundant amine (160 million tons/year) ${ }^{[22]}$ remains unsolved and this reaction has been listed as one of the top ten challenges for catalysis. ${ }^{\text {[23] }}$

The hydroamination of non-activated alkenes with $\mathrm{NH}_{3}$ has been previously unsuccessful because of the following hurdles:

- The bond dissociation energy of $\mathrm{NH}_{3}$ is as high as 415 $\mathrm{kJ} / \mathrm{mol} .{ }^{[24,25]}$ Ammonia can be activated by transition metals according to three different ways (i) deprotonation, (ii) 
oxidative addition and (iii) hydrogen atom transfer. ${ }^{\text {[26-30] }}$ Although the $\mathrm{N}-\mathrm{H}$ bond of $\mathrm{NH}_{3}$ can be weaken by transition metals, for instance molybdenum-based complexes can weakened by $54 \%$ the $\mathrm{N}-\mathrm{H}$ bond dissociation of ammonia, ${ }^{[31]}$ none of them was capable of catalyzing the hydroamination of alkenes with $\mathrm{NH}_{3}$,

- The strong coordination or adsorption of $\mathrm{NH}_{3}$, or in situ produced primary amines, on the catalyst prevents the coordination/adsorption of the alkenes, thus rapidly deactivating the whole catalytic system, ${ }^{[7-11]}$

- As mentioned above, the hydroamination of nonactivated alkenes with $\mathrm{NH}_{3}$ is thermoneutral and the entropy balance of this reaction is negative, thus preventing the use of high temperatures. ${ }^{[13]}$ In the case of $\mathrm{NH}_{3}$, the activation energy barrier is high due to strong electrostatic repulsions of the nitrogen electron lone pair with the electron-rich $\pi$ electron cloud of the alkene. ${ }^{[32]}$ Although a [2+2] cycloaddition could be an option, this route has to be also discarded due to a large HOMO $(\mathrm{N}-\mathrm{H}) /$ LUMO $(\mathrm{C}=\mathrm{C})$ energy gap and an orbital symmetry forbidden nature of a concerted reaction. ${ }^{[3-34]}$ From a thermodynamic point of view, this reaction should be favored at low temperatures, high pressures and with a high ammonia/alkene ratio.

\subsection{Homogeneous catalysts}

In the presence of molecular catalysts, successful goldcatalyzed hydroamination reaction with ammonia was reported feasible only using alkynes or allenes instead of alkenes. ${ }^{[35,36]}$ Hydroamination of alkynes is indeed thermodynamically more favorable than that of alkenes. For instance, the addition of ammonia to acetylene is approximately $70 \mathrm{~kJ} / \mathrm{mol}$ more exothermic than the addition to ethylene. ${ }^{[12]}$ To the best of our knowledge, there is no molecular catalyst capable of catalyzing the hydroamination of non-activated alkenes with ammonia, although much efforts have been done to predict the "ideal" catalyst and conditions by DFT. ${ }^{[37-42]}$
In this field of research, a pioneer work was reported by Whitman in $1954 .{ }^{[43]}$ He showed that alkali metals such as $\mathrm{Na}$, $\mathrm{Li}$, and their corresponding hydrides, catalyze the hydroamination of ethylene with ammonia, leading to a mixture comprising of ethyl, diethyl and triethylamine, in an overall yield of $70 \%$ (Fig. 7). The reaction was performed at $175-200^{\circ} \mathrm{C}$, but at a very high pressure (800-1000 atm) to thermodynamically favor the reaction. Side isomerization and polymerization of the alkene, and the use of very high pressures, represent important drawbacks for implementation on a larger scale.

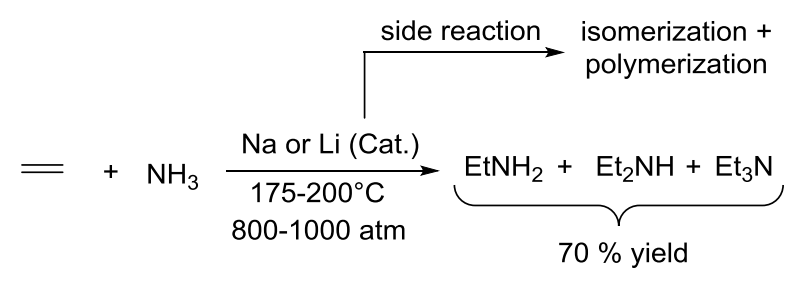

Figure 7. Hydroamination of ethylene with ammonia catalyzed by alkali metals

\subsection{Heterogeneous catalysts}

In 1987, Deepa investigated the catalytic activity of various acidic zeolites in the gas-phase hydroamination of ethylene with ammonia. ${ }^{[44]}$ They found that the presence of Bronsted acid sites (presumably $\mathrm{NH}_{4}{ }^{+}$under ammonia pressure), was mandatory to activate the alkene, through the formation of a carbenium ion, which subsequently reacts with ammonia to give ethylamine. To facilitate the desorption of ethylamine from the acid sites, a high temperature of $360^{\circ} \mathrm{C}$ was required. Therefore, it yields ethylamine in a low $13 \%$ yield at the thermodynamic equilibrium, even at a total pressure of about 60 bar. Best zeolites were $\mathrm{H}$-offretite, $\mathrm{H}$-clinoptilolite and $\mathrm{H}$-erionite, the latter being less prone to deactivation (Table 1, entries 1-3). ${ }^{[42]}$ The reaction proceeding through a carbenium

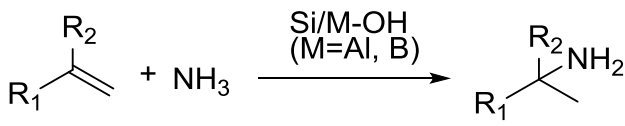

$$
\begin{aligned}
& \mathrm{R}_{1}=\mathrm{R}_{2}=-\mathrm{H} \\
& \mathrm{R}_{1}=\mathrm{R}_{2}=-\mathrm{Me} \\
& \mathrm{R}_{1}=\mathrm{H}, \mathrm{R}_{2}=-\mathrm{C}_{2} \mathrm{H}_{5}
\end{aligned}
$$

\begin{tabular}{|c|c|c|c|c|c|c|}
\hline Entry & Alkene & Catalyst & $\mathrm{NH}_{3} /$ Alkene ratio & Temp. $\left({ }^{\circ} \mathrm{C}\right)$ & Pressure (bar) & ${\text { Yield }(\%)^{[\mathrm{a}]}}$ \\
\hline 1 & ethylene & H-offretite & 4 & 360 & 55 & 11 \\
\hline 2 & ethylene & H-clinoptilolite & 4 & 360 & 55 & 13 \\
\hline 3 & ethylene & H-erionite & 4 & 360 & 55 & 10 \\
\hline 4 & isobutene & $\begin{array}{c}\text { Aluminosilicate and } \\
\text { borosilicate with } \\
\text { pentasil structures }\end{array}$ & 1.5 & 300 & 300 & 16 \\
\hline 6 & 1-butene & $\mathrm{H}-\mathrm{MFI}$ & 1 & 320 & 40 & 5 \\
\hline
\end{tabular}

[a] yield to primary amine (selectivity $>90 \%$, secondary amines are the other product formed) 
intermediate, it was next transposed to isobutene which is more reactive than ethylene, thanks to the intermediate formation of a tertiary carbenium cation(Fig. 8). ${ }^{[46,47]}$ From isobutene, the thermodynamic equilibrium was reached faster, but the yield to tert-butylamine was not significantly higher (16\% yield, Table 1 , entry 4$)$. This gas phase reaction was optimized and commercialized by BASF using aluminosilicate and borosilicate catalysts having pentasil structures. ${ }^{[48]}$ With a $\mathrm{NH}_{3}$ /isobutene molar ratio of 1.5 , at $300^{\circ} \mathrm{C}$ and under 300 bar, isobutene conversion range from 9 to $17 \%$ and selectivity to tert-butylamine higher than $95 \%$ were obtained (Table 1, entries 4,5 ). This process was however stopped few years later, presumably due to economic reasons. Other alkenes such as 1-butene and propylene were also tested through this process but yields of primary amines remained too low $(<5 \%)$ for an industrial development (Table 1, entry 6). ${ }^{[49]}$

In 2019, Bell re-explored the hydroamination of isobutene with $\mathrm{NH}_{3}$ using various zeolites. ${ }^{[50]}$ He showed that small and medium pore size zeolites with 1D channel were poorly active due to pore blockage caused by the adsorption of tertbutylamine $\left(\Delta \mathrm{H}_{\mathrm{ads}}\right.$ of tert-butylammonium ion $=200-250$ $\mathrm{kJ} / \mathrm{mol}$ ) on the catalyst surface. ${ }^{[49,50]}$ Tert-butylamine is indeed slightly more basic than $\mathrm{NH}_{3}\left(\mathrm{pKa}_{\mathrm{NH} 3}=9.23\right.$ vs 10.68 for ${ }^{t} \mathrm{BuNH}_{2}$ ) and thus stronger interacts with acid sites (Fig 8). As a result, its desorption requires an elevated temperature, which unfortunately competes with the Hoffman degradation of tertbutylamine, regenerating isobutene and $\mathrm{NH}_{3}$. By means of DFT calculations, authors confirmed that the heat of adsorption of tert-butylamine over $\mathrm{MFI}$ at $473 \mathrm{~K}\left(\Delta \mathrm{H}_{\mathrm{ads}}=-189 \mathrm{~kJ} / \mathrm{mol}\right)$ is higher than that of $\mathrm{NH}_{3}$ or isobutene $\left(\Delta \mathrm{H}_{\mathrm{ads}}=-60 \mathrm{~kJ} / \mathrm{mol}\right)$. At low tert-butylamine partial pressures, the desorption of tertbutylamine is rate-limiting while at higher partial pressures, the protonation of isobutene is the rate determining step. The subsequent addition of $\mathrm{NH}_{3}$ on the carbenium ion is barrierless. As previously observed, the deactivation rate of zeolites such as $\mathrm{H}-\mathrm{MFI}$ is rather slow because acid sites are passivated by the adsorption of $\mathrm{NH}_{3}$ or tert-butylamine, thus avoiding the cracking or oligomerization of isobutene which normally occurs over strong acid sites.

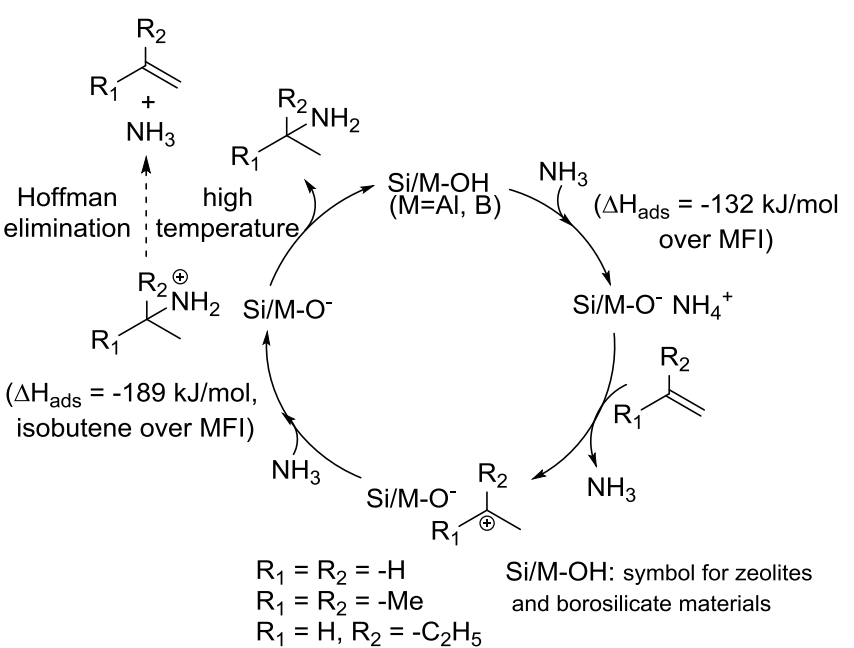

Figure 8. Schematic representation of the plausible hydroamination catalytic cycle over Bronsted solid acid.
It is worth mentioning in this section that enzymatic hydroamination of alkenes with ammonia has been also documented. $\mathrm{Li}$ reported the enzymatic intermolecular hydroamination of alkenes with ammonia, in an antiMarkovnikov fashion. ${ }^{[51]}$ Strictly speaking, this biotransformation is not a real hydroamination reaction as it involves a cascade of enzymatic reactions: epoxidation-isomerization-amination. Although good yields were claimed, to date, this enzymatic process was only applicable to activated alkenes such as aryl alkenes.

\section{Let's think differently}

In 2019, Swiderek proposed a completely different approach and reported the catalyst free hydroamination of ethylene with ammonia upon exposure to low-energy electrons (impacting on an ethylene/ammonia multilayer films) in an ultra-high vacuum chamber $\left(10^{-10}\right.$ Torr) (Fig. 9). ${ }^{[52]}$ This work brings two major contributions:

Without any catalyst, the adsorption/desorption of alkenes/alkyl amines on/from the catalytic sites is no longer a problem,

The irradiation of ethylene or ammonia with electrons at an $E_{0}(15 \mathrm{eV})$, slightly above (4 to $5 \mathrm{eV}$ ) their ionization threshold, removes one electron either from ethylene or ammonia, leading to the formation of a radical cation. Hence, this methodology has the advantage of circumventing the electrostatic repulsion between ethylene and ammonia, thus lowering the activation energy barrier. Using this technology, formation of ethylamine was clearly evidenced by thermal desorption spectrometry. The hydroamination rate increases with increasing the $E_{0}$ value showing that the reaction is ionization-driven. However, when the $E_{0}$ is too high, fragmentation occurs. Unfortunately, quantification and isolation of ethylamine was not feasible, hence no yield, conversion or selectivity were provided.

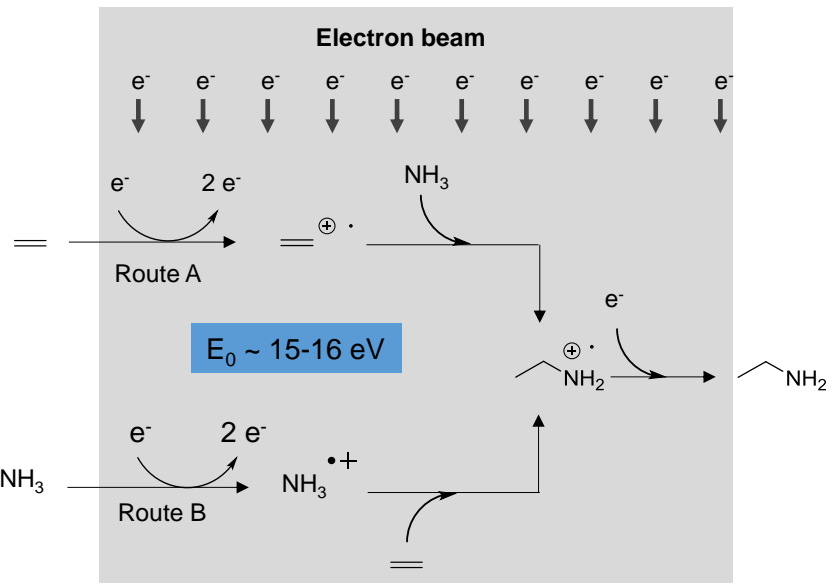

Figure 9. Catalyst-free hydroamination of ethylene with ammonia induced by low energy electron beam. 
Later on, this work was extended to other alkenes such as 1hexene, 1,5-hexanediene, Z/E 4-methyl-pent-2-ene, etc. ${ }^{[53]}$ It was shown that the reaction was still ionization-driven but the reaction mechanism becomes much more complex with these alkenes because of the occurrence of side fragmentation, resulting to alkene dimerization as well as formation of larger hydrocarbons.

In another way, Schwarz observed the hydroamination reaction of ethylene in the presence of $\mathrm{Ni}\left(\mathrm{NH}_{2}\right)^{+}$species, which were generated in a mass spectrometer of quadrupole/hexapole/quadrupole configuration (Fig. 10). ${ }^{[54]}$ When ethylene was introduced in the mass spectrometer $\mathrm{C}_{2} \mathrm{H}_{6} \mathrm{~N}^{+}$and $\mathrm{Ni}\left(\mathrm{C}_{2} \mathrm{H}_{4} \mathrm{~N}\right)^{+}$species were detected, together with the co-production of $\mathrm{H}_{2}$ in the latter case. The $\mathrm{Ni}\left(\mathrm{C}_{2} \mathrm{H}_{4} \mathrm{~N}\right)^{+}$ complex can even further react with another molecule of ethylene yielding $\mathrm{Ni}\left(\mathrm{C}_{4} \mathrm{H}_{6} \mathrm{~N}\right)^{+}$. In a similar way, authors showed that $\bullet \mathrm{NH}_{2}$ radicals and nitrene species could be formed from $\mathrm{NH}_{3}$ over $\left[\mathrm{Al}_{2} \mathrm{O}_{3}\right]^{+} \cdot$ generated by collision-induced dissociation under ultra-high vacuum in a mass spectrometer. ${ }^{[55]}$ Like $\cdot \mathrm{NH}_{2}$ radicals, nitrene are also very interesting species, as they are known to further react with $\mathrm{C}=\mathrm{C}$ bond to form amines, showing the contribution of auxiliary promotional tools for hydroamination reactions. Although, as in the case of Swiderek, ${ }^{[52,53]}$ all these species were only detected in a mass spectrometer and no yield, conversion or selectivity were provided, these study definitely showed that $\mathrm{Ni}\left(\mathrm{NH}_{2}\right)^{+}$and $\left[\mathrm{Al}_{2} \mathrm{O}_{3}\right]^{+}$• could be, in theory, promising catalysts for the hydroamination reaction of non-activated alkenes with $\mathrm{NH}_{3}$.

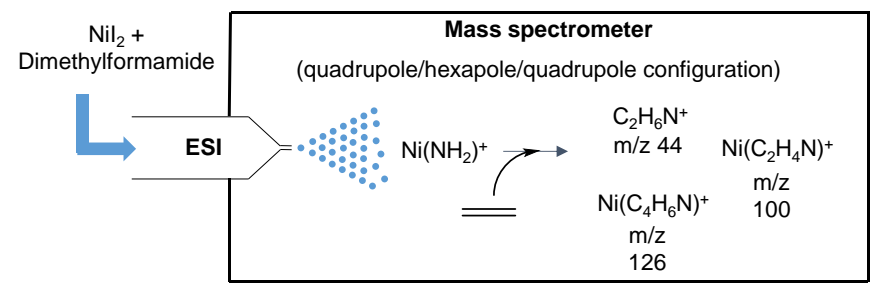

ESI: electrospray ionization

Figure 10. Reaction of $\mathrm{Ni}\left(\mathrm{NH}_{2}\right)^{+}$with ethylene in a QHQ-ESI mass spectrometer

\section{Inspiration for the future}

The hydroamination reaction has become very popular between 2005 and 2015, with a special focus on intramolecular reactions and/or the use of activated alkenes/amines. Since 2015, the number of articles published per year on hydroamination reactions is steadily decreasing reflecting the loss of the momentum achieved so far, mainly because of the difficulty for the scientific community to find efficient routes to couple alkenes with ammonia, or at least simple amines. Results presented in the section "Let's think differently" shows that hydroamination of alkenes with $\mathrm{NH}_{3}$ would deserve to be viewed from a radically different angle. In this context, the rapid development of "physical" methods for the activation of $\mathrm{NH}_{3}$ at low temperature, often resulting in the formation of electrophilic nitrogen radicals, opens formidable perspectives to the field not only to couple more efficiently ammonia with alkenes, but also to reverse the regioselectivity

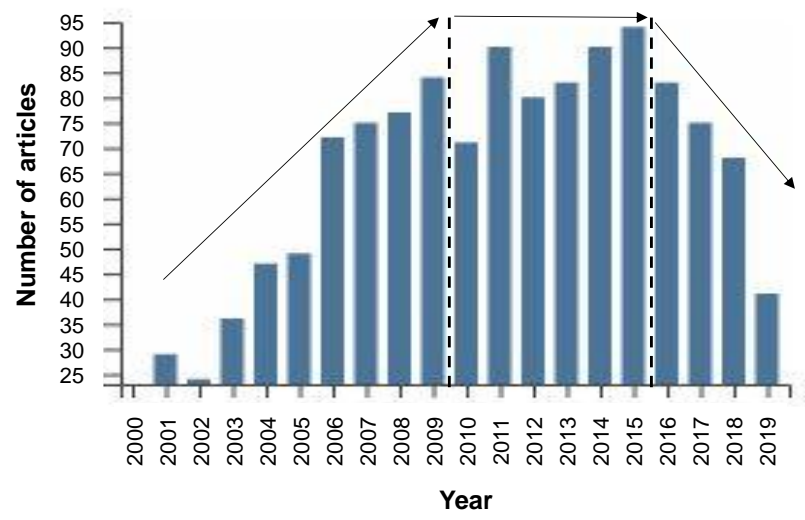

Figure 11. Number of articles published each year on hydroamination reactions Source Web of Science using "Hydroamination" as a keyword in title searchDone on July $23^{\text {rd }}, 2019$

to anti-Markovnikov products. So far, the works reported by Swiderek ${ }^{[52,53]}$ and Schwarz ${ }^{[54]}$ were performed under vacuum or at very low partial pressure of $\mathrm{NH}_{3}$. Adapting these alternative technologies to convert $\mathrm{NH}_{3}$ in a liquid phase is clearly highly desirable, but it remains a very difficult scientific task. In liquid phase, many alternative technologies such as electrochemistry, photochemistry, $\gamma$-ray irradiation, electron beam, non-thermal atmospheric plasma, high frequency ultrasound, among others, can convert $\mathrm{NH}_{3}$ to $\mathrm{NH}_{2}$ radical or $\mathrm{NH}_{3}{ }^{+} \cdot$ radical cation without assistance of any catalyst. However, most of these works were explored in water and $\mathrm{NH}_{x}$ radicals were partly scavenged by $\cdot \mathrm{OH}$ radicals, $\mathrm{H}_{2} \mathrm{O}, \mathrm{O}_{2}$ or in situ produced $\mathrm{H}_{2} \mathrm{O}_{2}$ to form undesirable $\mathrm{NO}_{x}$, including nitrite, nitrate and nitric acid, and also explosive chemicals such as hydroxylamine $\left(\mathrm{NH}_{2} \mathrm{OH}\right)$. This is exemplified by a recent study from Yoshida who showed that $\bullet \mathrm{NH}_{2}$ radicals could be formed in aqueous $\mathrm{NH}_{3}$ solution over $\mathrm{TiO}_{2}$ photocalalysts, which also underwent addition to alkenes in an anti-Markovnikov fashion. ${ }^{[56]}$ Although fair to good yields of primary alkyl amines were claimed, the use of water drastically limits the applicability of this work on a large scale due to (i) the low solubility of alkenes, (ii) the low stability of such photocatalysts in water and, more problematic, (iii) the unavoidable side oxidation of $\mathrm{NH}_{3}$ to $\mathrm{NO}_{x}$, which probably largely occurs in this work.

Producing $\bullet \mathrm{NH}_{2}$ radicals or $\mathrm{NH}_{3}{ }^{+} \cdot$ cation radicals in inert organic solvents containing alkenes, instead of water, would be clearly the ideal situation to optimize the hydroamination reaction selectivity. To date, activation of $\mathrm{NH}_{3}$ in organic media using these alternative technologies remains quasi unexplored and it represents, in our views, a very important area where the topic should now evolve. With this strategy, one of the biggest scientific challenges will consist in finding a compromise between kinetics and thermodynamics to (1) maximize the formation of $\cdot \mathrm{NH}_{2}$ radicals or $\mathrm{NH}_{3}^{+} \cdot$ cation radicals, i.e. avoid 
the complete decomposition of $\mathrm{NH}_{3}$ to $\mathrm{N}_{2}$ and $\mathrm{H}_{2}$, and (2) quickly trap $\cdot \mathrm{NH}_{2} / \mathrm{NH}_{3}{ }^{+} \cdot$ radicals with the alkene to prevent the side formation of hydrazine, stemming from the recombination of $\mathrm{NH}_{2}$ radicals, and the polymerization of the alkene. The coupling of these technologies with catalysis may be one of the solution to better control the selectivity of the reaction. The effectiveness of combining catalysis with auxiliary promotional tools has been reviewed by $\mathrm{N}$. Yan ${ }^{[57]}$ and is now emerging as a fascinating topic. We may cite in this tutorial review the hydrogenation of $\mathrm{N}_{2}$ as a case in point, as it can be also a potential source of inspiration for the formation of $\mathrm{NH}_{2}$ species. The activation of $\mathrm{N}_{2}(0.8 \mathrm{eV}$, rate-limiting step with catalysts in the synthesis of $\mathrm{NH}_{3}$ ) with auxiliary promotional tools such as ultrasound, plasma, electron beam, among others could assist catalysts in the hydrogenation of $\mathrm{N}_{2}$. In addition, the possibility to quickly tune the temperature or the pressure on the catalyst surface with the aid of these auxiliary promotional tools open unique conditions to thermodynamically favour reactions that are hardly feasible with "conventional" catalytic routes, such as hydroamination reactions.

\section{Conclusion}

To date, the catalytic hydroamination of non-activated alkenes with ammonia is still unsolved and this reaction remains a formidable challenge for catalysis. By analyzing the current academic and industrial literature, we summarize below the main hurdles facing by this reaction:

thermodynamics, the reaction is thermoneutral and the entropy balance of the reaction is negative, hence low temperatures and high pressures are required, the high bond dissociation energy of ammonia,

high energy barriers, caused by electrostatic repulsions of the nitrogen electron lone pair of $\mathrm{NH}_{3}$ with the $\pi$-electron cloud of the alkene,

the strong coordination/adsorption of $\mathrm{NH}_{3}$ and primary amines on catalytic sites, preventing the coordination/adsorption of the alkene and even, in some cases, deactivating the catalyst,

Primary amines are more nucleophilic and basic than $\mathrm{NH}_{3}$, a problem to selectively stop the reaction to the primary amines stage.

Radical-mediated mechanism appears to be a judicious approach to overcome most of these hurdles. The formation of - $\mathrm{NH}_{2} / \mathrm{NH}_{3}{ }^{+}$. radicals from $\mathrm{NH}_{3}$ is expected to not only reduce the activation energy barriers, and thus the required temperatures for the reaction, but also reverse the regioselectivity to complete anti-Markovnikov addition. In addition, results published by Knowles ${ }^{[19,20]}$ and Yoshida ${ }^{[56]}$ on photocatalysis suggest that the formation of secondary and tertiary amines is disfavored in the presence of $\cdot \mathrm{NH}_{2} / \mathrm{NH}_{3}{ }^{+}$. radicals, allowing reaching high selectivity to primary amines.

Working on alternative technologies, such as electron beam or non-thermal atmospheric plasma for instance, is a real source of inspiration for the future, as these technologies can convert $\mathrm{NH}_{3}$ to $\cdot \mathrm{NH}_{2} / \mathrm{NH}_{3}{ }^{+} \cdot$ radicals at low temperature, and without assistance of any catalyst. We are convinced that these technologies could assist catalysis in the activation of ammonia at low temperature, while keeping a catalytic control of the reaction selectivity. The development of such technologies (often at the border of chemistry and physics) for hydroamination reactions has the potential to revisit this challenging reaction and to open an unexplored field of research with huge scientific and societal impact.

Furthermore, the rapid progress made in recent years in the field of materials, molecular chemistry and biotechnologies, coupled with the development of digital, has led to a massive increase in the flow of information on catalysts. Integrating new solutions stemming from artificial intelligence and machine learning in chemistry might be also a solution to open novel horizons in hydroamination reactions, especially to select, or even create, more efficient catalysts that we hardly suspect today.

\section{Conflicts of interest}

There are no conflicts to declare.

\section{Acknowledgements}

The CNRS, the University of Poitiers, SOLVAY and the Région Nouvelle Aquitaine are strongly acknowledged for their financial supports.

\section{Notes and references}

1 https://www.marketsandmarkets.com/MarketReports/amines-market-

724.html?gclid=CjOKCQjw1MXpBRDjARIsAHtdNOchzctnFujU1Bm6A6NyTad5Mlki0OsZ3dgErXEIEaxr2jZ5BUSh kMaAjJWEALw_wcB

2 http://alkylamines.com/corporate/index.htm

3 https://ihsmarkit.com/products/alkylamines-chemicaleconomics-handbook.html

4 https://www.grandviewresearch.com/press-release/globalamines-market

5 L. Legnani, B. N. Bhawal, B. Morandi, Synthesis 2016, 49, 776789.

6 J. I. van der Vlugt, Chem. Soc. Rev., 2010, 39, 2302-2322.

7 J. Seayad, A. Tillack, C. G. Hartung, M. Beller, Adv. Synth. Catal. 2002, 344, 795-813.

8 T. E. Müller, K. C. Hultzsch, M. Yus, F. Foubelo, M. Tada, Chem. Rev. 2008, 108, 3795-3892.

9 T. E. Müller, M. Beller, Chem. Rev. 1998, 98, 675-703;

10 L. Huang, M. Arndt, K. Gooßen, H.h Heydt, L. J. Gooßen, Chem. Rev., 2015, 115 (7), 2596-2697.

11 S. Hong, T. J. Marks, Acc. Chem. Res. 2004, 37, 673-686.

12 Y. Li, T. J. Marks, J. Am. Chem. Soc. 1996, 118, 9295-9306.

13 J.-S. Ryu, G. Yanwu Li, T. J. Marks, J. Am. Chem. Soc. 2003, 125, 12584-12605.

14 D. R. Coulson, Tet. Lett., 1971, 5, 429-430.

15 R. Taube in Applied Homogenous Catalysis with Organometallic Compounds (Eds.: B. Cornils, W. A. Herrmann), Wiley-VCH, Weinheim, 2000, pp. 507-520.

16 V. Khedkar, A. Tillack, C. Benisch, J.-P. Melder, M. Beller, J. Mol. Cat. A Chem. 2005, 241, 175-183. 
17 A. L. Reznichenko, H. N. Nguyen, K. C. Hultzsch, Angew. Chem. Int. Ed. 2010, 49, $8984-8987$.

18 A. J. Musacchio, L. Q. Nguyen, G. H. Beard, R. R. Knowles, J. Am. Chem. Soc., 2014, 136, 12217-12220.

19 A. J. Musacchio, B. C. Lainhart, X. Zhang, S. G. Naguib, T. C. Sherwood, R. R. Knowles, Science, 2017, 355, 727-730.

20 D. C. Miller, J. M. Ganley, A. J. Musacchio, T. C. Sherwood, W. R. Ewing, R. R. Knowles, J. Am. Chem. Soc., 2019, 141, 42, 16590-16594.

21 S. W. Lardy, V. A. Schmidt, J. Am. Chem. Soc. 2018, 140, $12318-12322$.

22 M. Kitano, Y. Inoue, Y. Yamazaki, F. Hayashi, S. Kanbara, S. Matsuishi, T. Yokoyama, S.-W. Kim, M. Hara, H. Hosono, Nat. Chem., 2012, 4, 934-940.

23 J. Haggin, Chem. Eng. News, 1993, 23-27.

24 J. J. Warren, T. A. Tronic, J. M. Mayer, Chem. Rev. 2010, 110, 6961-7001.

25 J. Hoover, Science, 2016, 707-708.

26 J. L. Klinkenberg, J. F. Hartwig, J. Am. Chem. Soc. 2010, 132, 11830-11833.

27 J. Zhao, J. S. Goldman, J. F. Hartwig, Science 2005, 307, 10801082.

28 T. Braun, Angew. Chem. Int. Ed. 2005, 44, 5012-5014.

29 T. W. Hudnall, J. P. Moerdyk, C. W. Bielawski, Chem. Commun., 2010, 46, 4288-4290.

30 D. Wendel, T. Szilvsi, D. Henschel, P. J. Altmann, C. Jandl, S. Inoue, B. Rieger, Angew. Chem. Int. Ed. 2018, 57, 14575 14579.

31 M. J. Bezdek, S. Guo, P. J. Chirik, Science, 2016, 354, 730-733.

32 E. Haak, S. Doye, Chem. Unserer Zeit 1999, 33, 296-303.

33 D. Steinborn, R. Taube, Z. Chem. 1986, 26, 349-359.

34 R. Hoffmann, R. B. Woodward, Science 1970, 167, 825-831.

35 G. Kovacs, A. Lledos, G. Ujaque, Angew. Chem. Int. Ed. 2011, 50, 11147-1115.

36 V. Lavallo, G. D. Frey, B. Donnadieu, M. Soleilhavoup, G.Bertrand, Angew. Chem. Int. Ed. 2008, 47, 5224-5228.

37 M. Hölscher, A. Uhe, W. Leitner, J. Organomet. Chem. 2013, 748, 13-20.

38 C. Greene, P. K. Grudzien, J. T. York, J. Organomet. Chem. 2017, 851, 122-135

39 C. E. Kefalidis, C. A. Tsipis, J. Comput. Chem. 2012, 33, 16891700.

40 A. Uhe, M. Hçlscher, W. Leitner, Chem. Eur. J. 2010, 16, 92039214.

41 A. Uhe, M. Hçlscher, W. Leitner, Chem. Eur. J. 2013, 19, 10201027.

42 H. M. Senn, P. E. Blöchl, A. Togni J. Am. Chem. Soc. 2000, 122, 4098-4107.

43 B. W. Howk, E. L. Little, S. L. Scott, G. M. Whitman, J. Am. Chem. Soc.1954, 767, 1899-1902.

44 M. Deeba, M. E. Ford, T. A. Johnson, J. Chem. Soc., Chem. Commun., 1987, 562-563.

45 M. Deeba, M. E. Ford, Zeolites, 1990, 10, 794-797.

46 M. Deeba, E. Ford, J. Org. Chem., 1988, 53 (19), 4594-4596.

47 M. Tabata, N. Mizuno, M. Iwamoto, Chem. Lett., 1991, 1027 1030.

48 K.S. Hayes, Appl. Catal. A Gen. 2001, 221, 187-195.

49 M. Lequitte, F. Figueras, C. Moreau, S. Huby, J. Catal. 1996, 163, 255-261.

50 C. R. Ho, L. A. Bettinson, J. Choi, M. Head-Gordon, A. T. Bell, ACS Catal. 2019, 9, 7012-7022.

51 S. Wu, J. Liu, Z. Li, ACS Catal., 2017, 7, 5225-5233.

52 T. Hamann, E. Böhler, P. Swiderek, Angew. Chem. Int. Ed. 2009, 48, 4643-4645.

53 E. Böhler, J. H. Bredehöft, P. Swiderek, J. Phys. Chem. C 2014, 118, 6922-6933.

54 R. Kretschmer, M. Schlangen, H. Schwarz, Angew. Chem. Int. Ed. 2012, 51, 3483-3488.
55 R. Kretschmer, Z.-C. Wang, M. Schlangen, H. Schwarz, Angew. Chem. Int. Ed., 2013, 52, 9513-9517.

56 S. Park, J. Jeong, K.-I. Fujita, A. Yamamoto, H. Yoshida, J. Am. Chem. Soc., just accepted manuscripts, https://doi.org/10.1021/jacs.0c04598.

57 M. J. Hulsey, C. W. Lim, N. Yan, Chem. Sci., 2020, 11, 14561468.

F. Jérôme got his $P h D$ in 2000 from the University of Burgundy in France. He then moved as a postdoc fellow at UC-Davis (USA) and then in France at the University of Rennes. In 2002, he was recruited as a CNRS researcher and then promoted as CNRS research director in 2011 at the Insitute of Chemistry of Poitiers (IC2MP). Currently, he is deputy director of IC2MP. His research largely concerns the development of new technologies for the

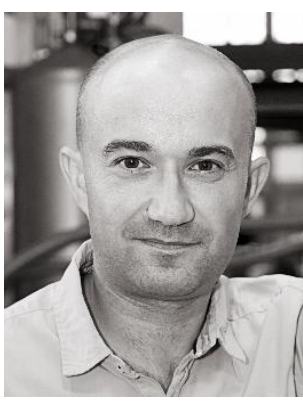
conversion of biomass to specialty chemicals, with a special interest on catalysis and its coupling with auxiliary promotional tools.

Stephane Streiff is director of Solvay's R\&I laboratory in China. The E2P2 laboratory is an international joint lab dedicated to eco-innovation and sustainable chemistry. His research concerns the development of new environmentally benign catalytic solutions and biomass valorization to high value chemicals. After his PhD in Organic Chemistry received at the University of Strasbourg, he moved first to Ruprecht-Karls-Universität University

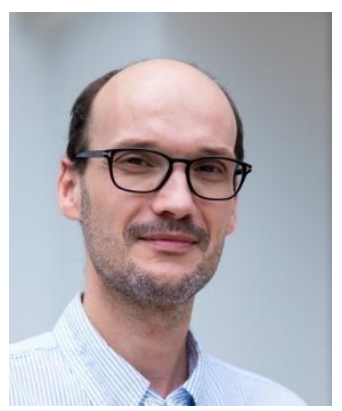
in Heidelberg for a Post Doc and then at the atomic Energy Commission in Paris. Stephane has more than 10 years experience in leading international Research and Innovation projects - as well in Business as in Corporate Research. 